\title{
Correction to: Transforming Education Outcomes in Africa
}

\author{
Johannes Hoogeveen and Mariacristina Rossi
}

\section{Correction to:}

\section{J. Hoogeveen and M. Rossi (eds.),}

Transforming Education Outcomes in Africa, https://doi.org/10.1007/978-3-030-12708-4

The original version of the book was inadvertently published as nonopen access. It has been now changed to open access with Copyright Holder Name: (C) 2019 International Bank for Reconstruction and Development/The World Bank. The correction to the book has been updated with the change. 